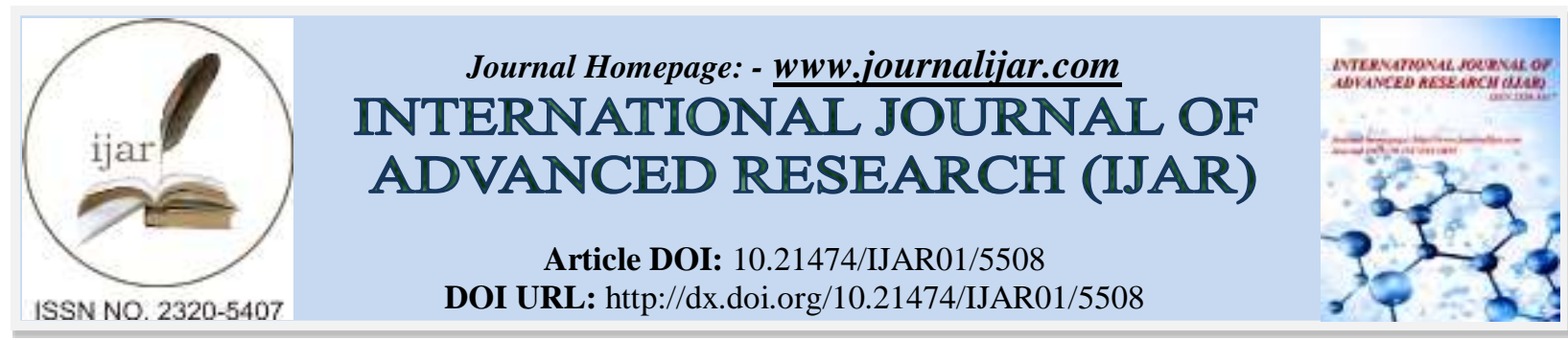

RESEARCH ARTICLE

\title{
ROLE OF HEPARIN BINDING EPIDERMAL GROWTH FACTOR IN THE SERUM AND FOLLICULAR FLUID IN PREDICTION OF PREGNANCY OUTCOME OF INFERTILE WOMEN WITH AND WITHOUT PCOS.
}

Saad Salih Al-Dujaily ${ }^{1}$, May Abdul-Kareem ${ }^{2}$ and Mohammad Oda Selman ${ }^{3}$.

1. Biotechnology Research Center, Al-Nahrain University, Baghdad-Iraq.

2. Kamal Al-Samarai IVF Hospital, Ministry of Health, Baghdad Iraq.

3. High Institute For Infertility Diagnosis and ART, Al-Nahrain University, Baghdad-Iraq.

\section{Manuscript Info}

Manuscript History

Received: 01 August 2017

Final Accepted: 03 September 2017

Published: October 2017

Key words:-

PCOS, female infertility, HB-EGF.

\section{Abstract}

Background: Successful implantation requires an intricate succession of molecular and genetic interactions. The implantation process is controlled by number of molecules like ovarian hormones, cytokines and growth factors which play an important role in regulating embryo differentiation, invasion and adhesion. During this time any breach in the communication between the endometrium and the embryo leads to implantation failure.

Aim of the study: to evaluate the role of Heparin binding epidermal growth factor (HB-EGF), measured in serum and follicular fluid in prediction of pregnancy outcome of infertile women with and without PCOS.

Patients and methods: A convenient sample of 100 infertile women undergoing intracytoplasmic sperm injection (ICSI) were intentionally divided, according to the cause of infertility, into 50 infertile women with polycystic ovary syndrome (PCOS) and 50 infertile women without PCOS. Heparin binding epidermal growth factor was measured on early follicular phase of the cycle (CD2-3) and at the day of ovarian pick up.

Results: Highly significant $(\mathrm{P}<0.001)$ increase were reported between PCOS and non-PCOS groups regarding estradiol $\left(\mathrm{E}_{2}\right)$ and HB-EGF levels in the serum follicular phase (day 2-3) and in the FF on day of ova pickup (OPU).In PCOS women, HBEGF in the serum of follicular phase and at day of OPU with its level in the FF at day of OPU were all significantly $(\mathrm{P}<0.05)$ higher in women with positive pregnancy outcome than those with negative pregnancy outcome.

Conclusion: Serum HB-EGF level is more valuable in predicting pregnancy out come in infertile PCOS women than non-PCOS women, and that serum HB-EGF level is more helpful than follicular fluid HBEGF level in predicting pregnancy outcome in infertile PCOS women. 


\section{Introduction:-}

About $12 \%$ of women had difficulty in getting pregnant or carrying a baby to term and the incidence of infertility clearly increases with age ${ }^{(1)}$.The normal pregnancy required successful fertilization, normal early embryonic development implantation and normal fetal growth till term ${ }^{(2,3)}$. The "window of implantation" or "window of receptivity is a limited time that reciprocal interactions between the embryo and the uterus must be executed within it ${ }^{(4)}$. During this time any breach in the communication between the endometrium and the embryo leads to implantation failure. An important cause of infertility is implantation failure ${ }^{(5)}$. The implantation process is controlled by ovarian hormones, cytokines and growth factors which play an important role in regulating trophoblast differentiation and invasion ${ }^{(6)}$.

Growth factors bind to specific receptors which present on cell surface and contain a tyrosine kinase domain in their C-terminus ${ }^{(7,8)}$.The epidermal growth factor family firmly interfere in implantation process .This family includes epidermal growth factor (EGF), amphiregulin (AR), heparin-binding epidermal growth factor (HB-EGF) and transforming growth factor alpha $(\mathrm{TGF} \alpha)^{(9)}$. At implantation TGF $\alpha$, HB-EGF and AR are expressed in the uterus; in particular, HB-EGF appears to be highly relevant to implantation. HB-EGF is not induced at the site of blastocyst attachment in cases of delayed implantation, but it is immediately induced after termination of delayed implantation by estrogen. Thus, the blastocyst signals the luminal epithelial cells at the site of attachment to express HB-EGF and the cells that expressed HB-EGF adhere only to active (not dormant) blastocysts ${ }^{(10)}$.

During the secretory phase of the menstrual cycle, HB-EGF is expressed in the human endometrium with highest expression occurring immediately prior to the window of implantation and during implantation in humans, HB-EGF is thought to play a role in both attachment and penetration. In cases of unexplained infertility, lower expression of HB-EGF was observed in the endometrium in the mid-secretory phase compared to normal endometrial ${ }^{(11)}$.It could therefore be considered as a good marker for the receptive endometrium and implantation window and it might have a role in both steps of attachment and penetration. The lifespan of pinopodes does not exceed $48 \mathrm{hr}$ in regularly menstruating women ${ }^{(12)}$.

On the other hand, the PCOS is the association of increase androgen level with chronic an ovulatory cycles in women without specific underlying diseases of the adrenal or pituitary glands. The recent application of modern, high-resolution diagnostic ultrasonography has again tipped the balance toward a more morphologically based diagnosis; however, there is great match between clinical biochemical and radiological findings ${ }^{(13)}$. Among women with anovulation and hirsutism presenting to a reproductive endocrine clinic, 30 percent of ovulatory women with amenorrhea and 75 percent of those with oligomenorrhea had ultrasonographic evidence of polycystic ovaries ${ }^{(14)}$.

A woman presenting with oligomenorrhea is likely to have the PCOS if she has one or more of these three features: polycystic ovaries on ultrasonography, hirsutism, and hyperandrogenemia ${ }^{(15)}$. The aim of the present study was to evaluate the role of HB-EGF in infertile women with and without PCOS and the possibility of prediction of implantation and then the pregnancy by measuring this marker in the serum and follicular fluid.

\section{Patients and methods:- \\ Study design:-}

This study was conducted at the High Institute for Infertility Diagnosis and Assisted Reproductive Techniques, AlNahrain University and at Kamal Al-Samarai IVF Hospital-Ministry of Health in Baghdad-Iraq, from November 2015 to September 2016. A convenient sample of 100 infertile women undergoing ICSI were intentionally divided, according to the cause of infertility, into 50 infertile women with PCOS and 50 infertile women without PCOS.

\section{History and physical examination:-}

All the couples underwent a complete history with physical examination (systemic and local, as outlined in the ASRM 2006 Practice Committee Opinion) in attempt to find the factors that could be the cause of impairing fertility.

\section{Investigations:-}

For women participating in the present study an early follicular phase, FSH and LH levels were assessed. Also serum $\mathrm{E}_{2}$ (on CD2) and progesterone (on CD21) were measured for assessment of ovarian function. HB-EGF was measured on early follicular phase of the cycle (CD2-3) and at the day of ovarian pick up. Hysterosalpingography (HSG) was performed to exclude tubal blockage. Ultrasound examination was performed. For male partners, standard seminal fluid examination was carried out as recommended by WHO 1999. 
In each group the women ovaries were stimulated by long GnRH agonist and antagonist protocol. Patients with elevated FSH levels and endocrine pathology were excluded from the study. Ovarian stimulation medication used included Gonal-F (75IU/vial) (Merck-Serono), Menogon (75 IU/vial) (Ferring)(Ovitrelle(6500IU/vial), (MerckSerono) and Pregnyl(5000IU/vial),( Organon) injection. Controlled ovarian hyperstimulation protocols included both GnRH agonist and GnRH antagonist protocols.

Oocytes retrieval was carried out 34 - 36 hours after the hCG injection under general anesthesia. oocytes were harvested by needle aspiration through the posterior fornix with a transvaginal ultrasound transducer guidance. Intracytoplasmic sperm injection (ICSI) was done according to standard procedure.

Embryo transfer was done on day 2 and 3 of embryonic development with or without assisted hatching, mostly two or three embryos were transferred depending on the recommendation of the couple and the quality of the embryos as recommended by Pandian et al ${ }^{(16)}$

Support of the luteal phase was performed by injecting $1500 \mathrm{IU}$ hCG(Ovidril, Company-Switzerland) immediately after oocyte retrieval and repeated seven days later for those how are not at risk of ovarian hyperstimulation syndrome(OHSS). Additionally, vaginal administration of $200 \mathrm{mg}$ of micronized progesterone (Duphstone,) three times a day, was started in the evening after oocyte pickup.

HB-EGF kit uses enzyme-linked immune sorbent (ELISA) based on biotin double antibody sandwich technology to assay Human HB-EGF ${ }^{(10,17)}$.

\section{Statistical analysis:-}

Data involved in the present study were analyzed using the statistical Package for Social Sciences (SPSS 22.0), Microsoft Office Excel 2010 and Medcalc 2010. Categorical variables were presented as number and percentage whereas numeric variables were expressed as mean, standard deviation, median and inter-quartile range. Kolmogrov Smirnov test was used to study normality distribution of numeric variables. Independent samples student t-test was used to study difference in mean value between two groups in case of normal distribution, whereas Mann Whitney U test was used to study difference in mean rank between two groups in case of non-normally distributed numeric variables. Wilcoxon test was used to study difference in mean rank between serum and follicular fluid samples. Receiver Operator Characteristic (ROC) curve analysis was carried out to calculated cutoff values with corresponding sensitivities and specificities. The level of significance was considered at P-value of equal or less 0.05 and highly significant level at $\mathrm{p}$-value equal or less than $0.01{ }^{(18)}$.

\section{Results:-}

Mean age of the entire women was $(32.10 \pm 5.66)$ years and there was no significant $(\mathrm{P}>0.05)$ difference in the mean age between non-PCOS group and PCOS group, $(31.72 \pm 5.45$ versus $32.48 \pm 5.89$ years, $\mathrm{P}=0.523)$. The women having primary infertility in the group of non-PCOS were slightly less than in the group of PCOS(34=66\%) versus $34=68 \%$ ), respectively. On the other hand, number and percentage of women complaining of secondary infertility were slightly more in the non-PCOS group than in the PCOS group, 17 (34\%) versus $16(32 \%)$, respectively, however, the difference was not statistically significant $(\mathrm{P}=0.832)$. Overall, the main cause of infertility observed in the entire samples was male factors, occurring in 38 (38\%) of women. In the non-PCOS group, the main cause of infertility was male factor followed by unexplained cause and then tubal factor, 26 (52\%), 17 (34\%) and 7 (14\%), respectively; While the main cause of infertility in the PCOS group was tubal factor, followed by unexplained factor and then male factor, $21(42 \%), 17(34 \%)$ and $12(24 \%)$, respectively. Overall, the difference in the distribution of causes of infertility among non-PCOS and PCOS group was statistically different $(\mathrm{P}=0.002)$. The percentage of women having tubal factor was significantly greater in the PCOS group than in the non-PCOS group ( $\mathrm{P}=0.044)$. Although, male factor was more frequent in the non-PCOS group than in the PCOS group, the difference did not reach statistical significance $(\mathrm{P}=0.112)$, table 1 .

Table 1:- Mean age and age range in subfertile women classified into PCOS and non-PCOS groups

\begin{tabular}{|l|l|l|l|l|}
\hline Characteristic & $\begin{array}{l}\text { Non-PCOS } \\
(\boldsymbol{n}=\mathbf{5 0})\end{array}$ & $\begin{array}{l}\text { PCOS } \\
(\boldsymbol{n}=\mathbf{5 0})\end{array}$ & $\begin{array}{l}\text { Total } \\
(\boldsymbol{n}=\mathbf{1 0 0})\end{array}$ & P-value \\
\hline Mean age \pm SD (years) & $31.72 \pm 5.45$ & $32.48 \pm 5.89$ & $32.10 \pm 5.66$ & $\begin{array}{l}0.523^{*} \\
\text { NS }\end{array}$ \\
\hline
\end{tabular}




\begin{tabular}{|c|c|c|c|c|}
\hline \multicolumn{5}{|l|}{ Infertility type } \\
\hline Primary, $\quad n(\%)$ & $33(66)$ & $34(68)$ & $67(67)$ & \multirow{2}{*}{$\begin{array}{l}0.832 \dagger \\
\text { NS }\end{array}$} \\
\hline Secondary, $n(\%)$ & $17(34)$ & $16(32)$ & $33(33)$ & \\
\hline \multicolumn{5}{|l|}{ Infertility cause } \\
\hline Unexplained, $n(\%)$ & $17(34)$ & $17(34)$ & $34(34)$ & Reference \\
\hline Tubal, $n(\%)$ & $7(14)$ & $21(42)$ & $28(28)$ & $\begin{array}{l}0.044 \\
\mathrm{~S}\end{array}$ \\
\hline Male, $n(\%)$ & $26(52)$ & $12(24)$ & $38(38)$ & $\begin{array}{l}0.112 \\
\text { NS }\end{array}$ \\
\hline
\end{tabular}

PCOS: polycystic ovary syndrome; $n$ : number of cases; SD: standard deviation; IQR: interquartile range; \%: percentage; * Mann Whitney U test; $\uparrow$ Chi-square test; NS: not significant.

The mean of total oocytes number, number of M1 oocytes and number of GV oocytes were in PCOS group were highly significantly $(\mathrm{P}<0.001)$ greater than that in non-PCOS group. In addition to that PCOS group showed no significant difference compare to non-PCOS group regarding to the number of total embryos, number of transferred embryos, number of grade 1 (G1) embryos and number of blastocyst stage $(\mathrm{P}=0.388)$, as shown in table (2).

Table 2:- Characteristics of ova and embryos in non-PCOS and PCOS groups

\begin{tabular}{|c|c|c|c|c|}
\hline \multicolumn{2}{|c|}{ Characteristic } & \multirow{2}{*}{$\begin{array}{l}\text { Non-PCOS }(\boldsymbol{n}=\mathbf{5 0}) \\
8.34 \pm 2.75\end{array}$} & \multirow{2}{*}{$\begin{array}{l}\operatorname{PCOS}(\boldsymbol{n}=\mathbf{5 0}) \\
11.16 \pm 3.70\end{array}$} & \multirow{2}{*}{$\begin{array}{l}\text { P } \\
<0.00 \\
\text { HS }\end{array}$} \\
\hline Ova & $\begin{array}{l}\text { Number of oocyte } \\
\text { (Mean } \pm \text { SD) }\end{array}$ & & & \\
\hline & M2 (Mean \pm SD) & $4.26 \pm 1.56$ & $4.70 \pm 2.53$ & $\begin{array}{l}0.796 \\
\text { NS }\end{array}$ \\
\hline & M1 (Mean \pm SD) & $2.60 \pm 1.14$ & $3.36 \pm 1.12$ & $\begin{array}{l}<0.001 \\
\mathrm{HS}\end{array}$ \\
\hline & GV $($ Mean \pm SD) & $1.48 \pm 0.81$ & $3.08 \pm 1.41$ & $\begin{array}{l}<0.001 \\
\mathrm{HS}\end{array}$ \\
\hline \multirow[t]{4}{*}{ Embryo } & $\begin{array}{l}\text { Number of embryos } \\
(\text { Mean } \pm \text { SD) }\end{array}$ & $5.70 \pm 2.54$ & $6.44 \pm 2.42$ & $\begin{array}{l}0.061 \\
\text { NS }\end{array}$ \\
\hline & $\begin{array}{l}\text { Number of embryo transfer } \\
(\text { Mean } \pm \text { SD) }\end{array}$ & $2.34 \pm 0.75$ & $2.24 \pm 0.74$ & $\begin{array}{l}0.448 \\
\text { NS }\end{array}$ \\
\hline & G1 (Mean \pm SD) & $2.28 \pm 0.69$ & $2.21 \pm 0.70$ & $\begin{array}{l}0.618 \\
\text { NS }\end{array}$ \\
\hline & Blastocyst (Mean \pm SD) & $2.88 \pm 0.35$ & $2.70 \pm 0.48$ & $\begin{array}{l}0.388 \\
\text { NS }\end{array}$ \\
\hline
\end{tabular}

PCOS: polycystic ovary syndrome; $n$ : number of cases; SD: standard deviation; * Mann Whitney U test; NS: not significant; S: significant; HS: Highly significant.

3-Hormones and growth factor levels in PCOS and non-PCOS groups:-

Highly significant differences were encountered between PCOS and non-PCOS groups regarding estradiol $\left(\mathrm{E}_{2}\right)$ level , and HB-EGF level in the serum at menstrual cycle day 2 and in the FF on day of ova pickup (OPU). All these variables were highly significantly $(\mathrm{P}<0.001)$ increase in $\mathrm{PCOS}$ groups in comparison with non-PCOS group, table (3).

Table 3:- Comparison of hormones and growth factor between PCOS and non-PCOS groups

\begin{tabular}{|l|l|l|l|}
\hline \multirow{2}{*}{ Hormone } & $\begin{array}{l}\text { Non-PCOS } \\
(\boldsymbol{n}=\mathbf{5 0})\end{array}$ & $\begin{array}{l}\text { PCOS } \\
(\boldsymbol{n}=\mathbf{5 0})\end{array}$ & \multirow{2}{*}{ * } \\
\cline { 2 - 3 } & Mean \pm SD & Mean \pm SD & \\
\hline $\mathrm{E}_{2}$ & $1428.10 \pm 570.83$ & $2057.60 \pm 578.82$ & $\begin{array}{l}<0.001 \\
\mathrm{HS}\end{array}$ \\
\hline Serum CD 2 HB-EGF & $272.31 \pm 121.61$ & $731.55 \pm 160.13$ & $\begin{array}{l}<0.001 \\
\mathrm{HS}\end{array}$ \\
\hline Serum OPU HB-EGF & $507.69 \pm 168.52$ & $1514.20 \pm 561.90$ & $\begin{array}{l}<0.001 \\
\mathrm{HS}\end{array}$ \\
\hline
\end{tabular}




\begin{tabular}{|l|l|l|l|}
\hline FF OPU HB-EGF & $499.05 \pm 168.51$ & $1481.70 \pm 560.16$ & $\begin{array}{l}<0.001 \\
\text { HS }\end{array}$ \\
\hline
\end{tabular}

*Mann Whitney U test; $n$ : number; SD: standard deviation; E2: estradiol; CD2: cycle day 2; HS: highly significant; FF: follicular fluid; OPU: oocyte pickup; HB-EGF: heparin binding epidermal growth factor like growth factor.

In table 4, the serum and follicular fluid HBEGF level has better sensitivity than serum estradiol in PCOS women ; however all parameters carry good prediction power since the area under the curve (AUC) is $>0.7$ with variation in sensitivity and specificity. Serum CD HBEGF of $\geq 535.35$ Serum OPU HBEGF of $\geq 843.94$ and FF OPU HBEGF of $\geq 829.84$ give sensitivities of $94 \%, 96 \%$ and $96 \%$ respectively.

Table 4:- Cutoff values that identify PCOS group

\begin{tabular}{|l|l|l|l|l|l|}
\hline Variable & $\begin{array}{l}\text { Cutoff value } \\
(>\text { or }=\text { ) }\end{array}$ & AUC & P & Sensitivity & Specificity \\
\hline E2 & 1679.00 & 0.782 & $<0.001$ & 72 & 72 \\
\hline Serum CD HBEGF & 535.35 & 0.991 & $<0.001$ & 94 & 100 \\
\hline Serum OPU HBEGF & 843.94 & 0.987 & $<0.001$ & 96 & 100 \\
\hline FF OPU HBEGF & 829.84 & 0.992 & $<0.001$ & 96 & 100 \\
\hline
\end{tabular}

\section{4-Biochemical pregnancy outcome in PCOS and non-PCOS groups:-}

Positive biochemical pregnancy was detected in 37 (37\%) of all women participating in the current study. failure of fertilization was observed in $2(2 \%)$ cases. The percentage of pregnancy was higher in PCOS than non-PCOS groups, $21(42.9 \%)$ versus $16(32.7 \%)$.However, this difference did not reach the statistical significance $(\mathrm{P}=0.297)$, as shown in table (5).

Table 5:- Percentage of pregnancy in PCOS and non-PCOS groups

\begin{tabular}{|l|l|l|l|l|l|}
\hline Pregnancy & $\begin{array}{l}\text { Non-PCOS } \\
(\boldsymbol{n}=\mathbf{4 9})\end{array}$ & $\begin{array}{l}\text { PCOS } \\
(\boldsymbol{n = 4 9 )}\end{array}$ & Total & $\chi^{2}$ & $\mathbf{P}_{\dagger}^{\dagger}$ \\
\hline Positive & $16(32.7)$ & $21(42.9)$ & $37(37.8)$ & 1.086 & 0.297 \\
\hline Negative & $33(67.3)$ & $28(57.1)$ & $61(62.2)$ & & NS \\
\hline Total & $49(100.0)$ & $49(100.0)$ & $98(100.0)$ & & \\
\hline
\end{tabular}

PCOS: polycystic ovary syndrome; $n$ : number of cases; test; NS: not significant; $\uparrow:$ Chi-Square test.

Regarding PCOS group, mean estradiol (E2) was significantly $(\mathrm{P}=0.018)$ higher in women with positive pregnancy outcome $(2298.80 \pm 475.73)$ than those with negative pregnancy outcome $(1911.00 \pm 582.12)$. In addition to that, serum CD HBEGF, serum OPU HBEGF and FF OPU HBEGF were all significantly $(\mathrm{P}<0.05)$ increment in women with positive pregnancy outcome than those with negative pregnancy outcome, as illustrated in table (6).

Table 6:- Hormone levels according to biochemical pregnancy outcome in PCOS group

\begin{tabular}{|l|l|l|l|}
\hline \multirow{2}{*}{ Characteristic } & $\begin{array}{l}\text { Positive pregnancy } \\
(\mathbf{n = 2 1})\end{array}$ & $\begin{array}{l}\text { Negative pregnancy } \\
(\mathbf{n = 2 8})\end{array}$ & P \\
\cline { 2 - 4 } & Mean \pm SD & Mean \pm SD & \\
\hline E2 & $2298.80 \pm 475.73$ & $1911.00 \pm 582.12$ & 0.018 \\
\hline Serum CD2 HBEGF & $796.82 \pm 133.33$ & $697.97 \pm 148.35$ & 0.025 \\
\hline Serum OPU HBEGF & $1694.90 \pm 439.66$ & $1415.70 \pm 595.40$ & 0.039 \\
\hline FF OPU HBEGF & $1623.30 \pm 433.61$ & $1408.40 \pm 614.50$ & 0.039 \\
\hline
\end{tabular}

Regarding non-PCOS group, mean estradiol (E2) was significantly $(\mathrm{P}=0.010)$ higher in women with positive pregnancy outcome than those with negative pregnancy outcome, $1703.90 \pm 618.75$ versus $1286.70 \pm 508.77$, in addition serum CD HBEGF, Serum OPU HBEGF and FF OPU HBEGF were all significantly $(\mathrm{P}<0.05)$ higher in women with positive pregnancy outcome than those with negative pregnancy outcome, as demonstrated in table (7).

Table 7:- Hormone levels according to biochemical pregnancy outcome in non-PCOS group

\begin{tabular}{|l|l|l|l|}
\hline Characteristic & $\begin{array}{l}\text { Positive pregnancy } \\
(\mathbf{n}=16)\end{array}$ & $\begin{array}{l}\text { Negative pregnancy } \\
(\mathbf{n}=33)\end{array}$ & P \\
\cline { 2 - 3 } & Mean \pm SD & Mean \pm SD & \\
\hline
\end{tabular}




\begin{tabular}{|l|l|l|l|}
\hline E2 & $1703.90 \pm 618.75$ & $1286.70 \pm 508.77$ & 0.010 \\
\hline Serum CD 2 activin A & $3.63 \pm 1.77$ & $2.48 \pm 1.59$ & 0.006 \\
\hline Serum OPU activin A & $6.07 \pm 1.94$ & $4.80 \pm 1.70$ & 0.022 \\
\hline FF OPU activin A & $6.02 \pm 1.91$ & $4.83 \pm 1.70$ & 0.025 \\
\hline Serum CD2 HBEGF & $330.19 \pm 121.35$ & $243.72 \pm 114.96$ & 0.011 \\
\hline Serum OPU HBEGF & $579.83 \pm 158.41$ & $470.55 \pm 165.95$ & 0.017 \\
\hline FF OPU HBEGF & $569.37 \pm 157.83$ & $463.08 \pm 166.97$ & 0.034 \\
\hline
\end{tabular}

\section{Discussion:-}

Hormones levels in PCOS and non-PCOS groups:-

The present study showed highly significant differences between PCOS and non-PCOS groups regarding estradiol $\left(E_{2}\right)$ level. Several studies reported that serum estradiol $\left(E_{2}\right)$ level is higher among women with PCOS than in healthy women ${ }^{(19,20)}$.

Regarding estradiol $\left(\mathrm{E}_{2}\right)$, One possible explanation of results in which PCOS group estradiol was far more than that of control group, is that our patients received controlled ovarian stimulation for ovulation induction and that however, the granulosa cells of patients with PCOS are functionally robust and exhibit increased estrogen responses to FSH stimulation compared to those of normal women, which may, in part, account for increased risk of ovarian hyperstimulation syndrome in PCOS women undergoing ovulation induction with gonadotropin therapy ${ }^{(21)}$.

The published literatures gave conflicting results, some of which were consistent with finding of our study in that serum estradiol (E2) is significantly higher in women with PCOS than in control women such as the finding of a recent Chinese study carried out in 2015 on 785 women with PCOS ${ }^{(22)}$.

\section{Growth factor levels in PCOS and non-PCOS groups:-}

For our best knowledge, after reviewing published articles, this is the first study to compare serum and follicular fluid HB-EGF between PCOS and non-PCOS control groups. Hence we cannot compare our results with other literatures.

It was stated, by several authors, that HB-EGF exists in two forms, the precursor membrane-anchored form and the mature secreted form. The soluble form maintains and enhances the proliferation and survival of granulose cells population, whereas the membrane form inhibits proliferation and survival of granulose cells population. These contradicting mechanism are mediated by either unidentified anti-apoptotic or pro-apoptotic pathways. On the other hand it was found that HB-EGF plays an important role in implantation of blastocyst ${ }^{(23,24)}$.

The findings of present work suggest that high HBEGF level in the serum and FF may play a role in the pathogenesis of PCOS; however, we cannot predict its exact role. Perhaps, its role in regulation of the population of growing granulosa cells is an essential step, but its link to maturation arrest of growing antral follicle cannot be explained. Further experimental and clinical studies are required to clarify this point.

The result of this study recorded that serum and FF of HB-EGF levels were significantly higher at day of ova pickup in both PCOS and non-PCOS groups. These changes suggest that HB-EGF is under control of gonadotrophins and that increase in the level of FSH and /or LH may play a role in stimulating increase level of HB-EGF. Similar results were reported by Lessey et al., who carried out an RNase protection assay (RPA) using RNA made from endometrium collected from different phases of the menstrual cycle and demonstrated increased HB-EGF expression to ward day of ovulation and reaching maximum level during the mid-secretory phase, time of implantation. Thus HB-EGF plays an important role for implantation ${ }^{(25)}$.

Biochemical pregnancy outcome in relation to the level of HB-EGF in the serum and follicular fluid:The results of the present study showed that Serum cycle day 2 (CD2) HBEGF, serum on day of ova pickup (OPU) HBEGF and follicular fluid (FF) on day of ova pickup (OPU) HBEGF were all significantly higher in women with positive pregnancy outcome than those with negative pregnancy outcome in both PCOS and non-PCOS groups. 
In the present study, the predictive cutoff values of serum cycle day 2 (CD2) HBEGF, Serum on day of ova pickup (OPU) HBEGF and follicular fluid (FF) on day of ova pickup (OPU) HBEGF were, 294.8, $536.2 \mathrm{ng} / \mathrm{ml}$ and 529.29 $\mathrm{ng} / \mathrm{ml}$ for non-PCOS group and $702.7 \mathrm{ng} / \mathrm{ml}, 1653.15 \mathrm{ng} / \mathrm{ml}$ and $1600.75 \mathrm{ng} / \mathrm{ml}$ for PCOS group, respectively.

In other words, serum HB-EGF level is more valuable in predicting pregnancy out come in infertile PCOS women than non-PCOS women, and that serum HB-EGF level is more helpful than follicular fluid HB-EGF level in predicting pregnancy outcome in infertile PCOS women.

\section{References:-}

1. Cong J, Li P, Zheng L, Tan J. Prevalence and Risk Factors of Infertility at a Rural Site of Northern China. Handelsman DJ, ed. PLoS ONE. 2016;11(5):e0155563.

2. Hawkins SM, Matzuk MM. Menstrual Cycle: Basic Biology. Annals of the New York Academy of Sciences. 2008;1135:10-18.

3. Aflalo ED, Sod-Moriah UA, Potashnik G, Har-Vardi I. Expression of plasminogen activators in preimplantation rat embryos developed in vivo and in vitro. Reprod Biol Endocrinol: RB\&E. 2005;3:7.

4. Zhang S, Lin H, Kong S, et al. Physiological and molecular determinants of embryo implantation. Molecular aspects of medicine. 2013;34(5):939-980.

5. Cakmak H, Taylor HS. Implantation failure: molecular mechanisms and clinical treatment. Human Reproduction Update. 2011;17(2):242-253.

6. Ai Z, Jing W, Fang L. Cytokine-Like Protein 1(Cytl1): A Potential Molecular Mediator in Embryo Implantation. Shen W, ed. PLoS ONE. 2016;11(1):e0147424.

7. Tuteja N. Signaling through G protein coupled receptors. Plant Signaling \& Behavior. 2009;4(10):942-947.

8. Lemmon MA, Schlessinger J. Cell signaling by receptor-tyrosine kinases. Cell. 2010;141(7):1117-1134.

9. Zeng F, Harris RC. Epidermal growth factor, from gene organization to bedside. Seminars in cell \& developmental biology. 2014;0:2-11.

10. Lim HJ, Dey SK. HB-EGF: a unique mediator of embryo-uterine interactions during implantation. Experimental cell research. 2009;315(4):619-626.

11. Aghajanova L, Giudice LC. Molecular Evidence for Differences in Endometrium in Severe Versus Mild Endometriosis. Reproductive Sciences. 2011;18(3):229-251.

12. Mitwally MF, Casper RF, Diamond MP. The role of aromatase inhibitors in ameliorating deleterious effects of ovarian stimulation on outcome of infertility treatment. Reprod Biol Endocrinol. 2005;3:54.

13. Sirmans SM, Pate KA. Epidemiology, diagnosis, and management of polycystic ovary syndrome. Clinical Epidemiology. 2014;6:1-13.

14. Barthelmess EK, Naz RK. Polycystic ovary syndrome: current status and future perspective. Frontiers in bioscience (Elite edition). 2014;6:104-119.

15. Lane DE. Polycystic ovary syndrome and its differential diagnosis. Obst Gynecol Surv. 2006;61(2):125-135.

16. Pandian Z, Templeton A,Serour G Bhattacharya S. Number of embryos for transfer after IVF and ICSI: a Cochrane review Hum Reprod, 2005. 20(10): 2681-2687.

17. Lerchbaum E, Schwetz V, Rabe T, Giuliani A, Obermayer-Pietsch B. Hyperandrogenemia in Polycystic Ovary Syndrome: Exploration of the Role of Free Testosterone and Androstenedione in Metabolic Phenotype. Eller P, ed. PLoS ONE. 2014;9(10):e108263.

18. Glover, T.and Mitchell, K.(2008).An introduction to Biostatistics, $2^{\text {nd }}$ ed. Waveland press .Inc.

19. Al-Dujaily SS and Alwan N S. Relationship between antiMüllerian ovarian hormone, activin-A, and follistatin hormones levels with pregnancy rate following intrauterine insemination. Iraqi J. Embryos and Infertility Researches. 2013; 3(6): 9-14.

20. Al-Hakeim HK and Ridha MA. Study of Activin A and Inhibin A Hormones levels in Polycystic Ovarian Syndrome and their Correlation with Other Biochemical Parameters. Magazin of Al-Kufa University for Biology. 2013; 5 (2): 1-9.

21. Ji S Z, Xiao-Ping C, Xiang WW, et al. Correlation analysis of inhibin B, follistatin and activin A in patients with polycystic ovary syndrome. African Journal of Microbiology Research. 2010; 4(12): 1295-1298.

22. Al-Hakeim H K and Ridha M A. Study of Activin A and Inhibin A Hormones levels in polycystic ovarian syndrome and their correlation with other biochemical parameters. Magazin of Al-Kufa University for Biology. 2013; 5 (2): 1-9.

23. Eldar-Geva T, Spitz IM, Groome NP, Margalioth EJ, Homburg R. Follistatin and activin A serum concentrations in obese and non-obese patients with polycystic ovary syndrome. Hum Reprod. 2001;16:25522556 . 
24. Vänttinen T, Liu J, Hydén-Granskog and Voutilainen. Biphasic regulation of activin A secretion bygonadotropins in cultured human ovarian granulosa-luteal cells leads to decreasing activin:inhibin ratios during continuing gonadotropin stimulation. Journal of Endocrinology. 2002; 172: 557-563 .

25. Lessey BA, Gui Y, Apparao KB, Young SL, Mulholland J. Regulated expression of heparin-binding EGF-like growth factor (HB-EGF) in the human endometrium: a potential paracrine role during implantation. Mol Reprod Dev. 2002 ;62(4):446-55 